\title{
Primary and Permanent Dental Caries: Having Differences between Gender?
}

\author{
Syed Adnan Ali ${ }^{1 *}$, Nazeer Khan ${ }^{2}$ and Mudassir Uddin ${ }^{1}$ \\ ${ }^{1}$ Department of Statistics, University of Karachi, Pakistan \\ ${ }^{2}$ Department of Biostatistics, Jinnah Sind Medical University, Pakistan
}

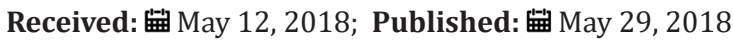

*Corresponding author: Syed Adnan Ali, Department of Statistics, University of Karachi, Pakistan

\begin{abstract}
Dental caries or breakdown of teeth is one of the frequent health problems from chronic disease among children and adults. Several studies showed a higher burden of this disease in their population, statistics showed 51\% Pakistani population getting effected with this disease, increased in body mass index, poor oral hygiene and sugar consuming at higher level are the common risk factors of this problem, our aim of study was to provide an estimated of primary and permanent decayed, filled and missing teeth among school going children of sind and KPK province of Pakistan and comparison of these two estimates between boys and girls, for this purpose secondary data of 3358 children was used and stata software gives the results of studied samples, this study concludes that in sind and KPK primary caries were significantly higher as compare to permanent caries and gender gives significant on dental caries.
\end{abstract}

Keywords: Dental Caries; Primary; Permanent; Gender

Abbreviations: BMI: Body Mass Index; DMFT: Decayed, Missing, Filled Permanent Teeth; DMFT: Decayed, Missing, Filled Primary Teeth; KPK: Kyber Pakhtunkhwa

\section{Background}

Dental caries or breakdown of teeth is one of the frequent health problems from chronic disease among children and adults. Several studies showed a higher burden of this disease in their population, Pakistan also victim of this disease a study reports, $51 \%$ of the sampled population was effected from dental caries [1] another study from north India reports the $36.5 \%$ prevalence of dental caries among aged 8- 15 years old children [2], studies shows, increase in body mass index [3] poor oral hygiene [4] sugar consuming at higher level [5], inappropriate methods of infant feeding and poverty [6] are the trend causes of dental caries that could increase the risk in population, literature also shows the prevalence of caries consistently got increase among children from aged 5 - 8 years old and subsequently went down among children of aged 11 - 15 years old [7], in comparison of male and female population, females found more effected as compared to male a study evident that women's oral health down more speedily as compare to men's oral health [8], to overcome on the worldwide increasing trend of this problem a proper diet plan, physical activity to control body mass index, and good oral hygiene practices are the need of time.

\section{Objective}

Objective of the current study was to provide an estimate of decayed, filled, and missing permanent and primary teeth among children's of sindh and Kyber Pakhtunkhwa (KPK) provinces of Pakistan, and comparison of these estimates among boys and girls to see the significance of results.

\section{Subjects and Method}

Part of a secondary baseline data for dental caries project of Pakistani children, funded by Higher Education Commission, 
Islamabad, titled 'Time and Sequence of Eruption Teeth of Pakistani Children [9]. The co-author of this study is the Principal Investigator of that Project.

\section{Sampling Technique}

We used secondary data in our research however at primary level in project [9] Multistage Systematic Cluster Random sampling was performed to collect the data on study variables includes age, gender, and type of school. The dentists were also examined the children for dental caries and eruption of teeth.

\section{Study Population}

School going children from Larkana city of Sindh province and Peshawar city of KPK province aged between 5 to 19 years.

\section{Statistical Analysis}

STATA 12.0 MP versions was used to find the study outcomes. Counts with percentages were reported for gender, body mass index categories, and oral hygiene, mean and standard deviation were reported for age, decayed, missing, filled primary, permanent and overall teeth, non parametric Mann Whitney U test was done to compare the mean difference for this outcomes among boys and girls samples, p-value less than 0.05 was considered significant (Figure 1). Percentiles were used to obtained the body mass index of children, samples who were measured at more than or equal to $95^{\text {th }}$ Percentile were categorized as obsess, those who were measured at the $85^{\text {th }}$ to $94^{\text {th }}$ percentiles were considered under overweight category, the range from $5^{\text {th }}$ percentile to $85^{\text {th }}$ percentile were considered in the normal weight and below the $5^{\text {th }}$ percentile were considered underweight as per world Health Organization criteria.

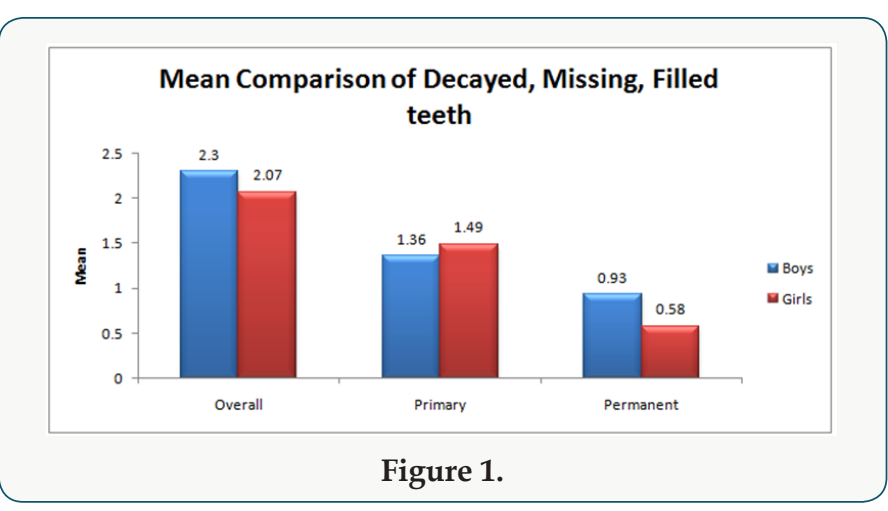

\section{Results}

Table 1 reports the samples statistics of respondents, there were 3358 children were examined, $47.8 \%$ were boys, body mass index measured on percentile basis and results showed that $4.9 \%$ samples were found underweight, $5 \%$ were obese and $10 \%$ were overweight, $45.7 \%$ had good oral hygiene while $39.1 \%$ had fair oral hygiene, the mean age of samples was 8.62 years with 2.19 standard deviation, the mean permanent (decayed, missing, filed) was 0.75 with 2.11 standard deviation, the mean primary (decayed, missing, filled) was 1.43 with 1.36 standard deviation, and the mean of overall (decayed, missing, filled) teeth was 2.18 with 2.49 standard deviation. Table 2 gives the mean comparison of decayed, missing, filled primary, permanent and overall teeth between boys and girls, results of Mann whitney $U$ test gives the evidence that, overall decayed, missing, and filled teeth were significantly higher among boys as compare to girls, $(\mathrm{p}=0.001)$ whereas mean decayed, missing and filled primary teeth were significantly higher among girls, $(p=0.014)$ however mean of decayed, missing, and filled permanent teeth were significantly higher among boys with $p$ $<0.01$.

Table 1: Samples statistics of respondents $(n=3358)$.

\begin{tabular}{|c|c|c|c|}
\hline \multicolumn{2}{|c|}{ Parameters } & $\mathbf{n}$ & $\%$ \\
\hline \multirow{2}{*}{ Gender } & Boys & 1604 & 47.8 \\
\hline & Girls & 1754 & 52.2 \\
\hline BMI & Underweight & 164 & 4.9 \\
\hline \multirow{3}{*}{ Categories } & Healthy Weight & 2651 & 80 \\
\hline & Overweight & 333 & 10 \\
\hline & Obese & 166 & 5 \\
\hline \multirow{3}{*}{ Oral Hygiene } & Good & 1535 & 45.7 \\
\hline & Fair & 1313 & 39.1 \\
\hline & Poor & 510 & 15.2 \\
\hline Age (years) & Mean, SD & 8.62 & 2.19 \\
\hline $\begin{array}{c}\text { Decayed, Missing, Filed } \\
\text { Permanent teeth }\end{array}$ & Mean, SD & 0.75 & 2.11 \\
\hline $\begin{array}{l}\text { Decayed, Missing, Filed } \\
\text { primary teeth }\end{array}$ & Mean, SD & 1.43 & 1.36 \\
\hline $\begin{array}{l}\text { Overall Decayed, Missing, } \\
\text { Filled teeth }\end{array}$ & Mean, SD & 2.18 & 2.49 \\
\hline
\end{tabular}

Table 2: Comparison of Mean Decayed, Missing and Filled teeth.

\begin{tabular}{|c|c|c|c|c|c|}
\hline & Gender & $\mathbf{N}$ & Mean & S.D & p-value \\
\hline \multirow{2}{*}{$\begin{array}{c}\text { Overall } \\
\text { Decayed, } \\
\text { Missing, Filled } \\
\text { teeth }\end{array}$} & Boys & 1604 & 2.3 & 2.503 & $0.001^{*}$ \\
\hline & Girls & 1754 & 2.07 & 2.489 & \\
\hline \multirow{2}{*}{$\begin{array}{c}\text { Decayed, } \\
\text { Missing, Filed } \\
\text { primary teeth }\end{array}$} & Boys & 1604 & 1.36 & 2.108 & $0.014^{*}$ \\
\hline & Girls & 1754 & 1.49 & 2.113 & \\
\hline \multirow{2}{*}{$\begin{array}{c}\text { Decayed, } \\
\text { Missing, Filed } \\
\text { Permanent } \\
\text { teeth }\end{array}$} & Boys & 1604 & 0.93 & 1.522 & $<0.01^{*}$ \\
\hline & Girls & 1754 & 0.58 & 1.187 & \\
\hline
\end{tabular}

\section{Discussion}

Results of this study showed that, one-fifth had problem of obesity, and around one-seventh of the total samples had problem of poor oral hygiene, literature on dental caries suggested that these two factors are directly associated with the dental caries, $[3,4]$ in our data some of the samples were found underweight the reason of this is low or insufficient diet that cannot be ignored, the mean 
of decayed, missing and filled overall teeth was 2.18, it was also increased as compare to study was done in the Quetta city [10], in the present study the mean of primary caries was higher as compare to the permanent caries, these findings also second the outcomes of study from US [11], it is also agreeing with the study that showed children from aged 5-8 years have positive trend of dental caries [7], mean permanent caries were significantly higher among boys, whereas primary caries were significantly low, however the overall caries were significantly higher among boys, and gender gives significant effect on outcomes of dental caries, literature gives the evidence that, girls are commonly get more affected from dental caries as compare to the boys [2].

\section{Conclusion}

This study concludes in sind and KPK, primary caries were significantly higher as compared to permanent caries among children from Pakistan, and gender gives significant effect on dental caries outcomes.

\section{References}

1. Dawani N (2012) Prevalence and factors related to dental caries among pre-school children of Saddar town: a cross-sectional study. BMC Oral Health 12(1): 59.

2. Plaka K (2017) Risk factors and prevalence of dental fluorosis and dental caries in school children of North India. Environmental monitoring and assessment 189(1): 40 .
3. Bagramian RA, F Garcia Godoy, AR Volpe (2009) The global increase in dental caries. A pending public health crisis. Am J Dent 22(1): 3-8.

4. Amin TT, BM Alâ€ Abad (2008) Oral hygiene practices, dental knowledge, dietary habits and their relation to caries among male primary school children. International journal of dental hygiene 6(4): 361-370.

5. Tinanoff N, CA Palmer (2000) Dietary determinants of dental caries and dietary recommendations for preschool children. Journal of public health dentistry 60(3): 197-206.

6. Petersen PE, MA Lennon (2004) Effective use of fluorides for the prevention of dental caries in the 21st century: the WHO approach. Community dentistry and oral epidemiology 32(5): 319-321.

7. Dash JK (2002) Prevalence of dental caries and treatment needs among children of Cuttack (Orissa). J Indian Soc of Pedodontics and Preventive Dentistry 20(4): 139-143.

8. Lukac, JR (2011) Sex differences in dental caries experience: clinical evidence, complex etiology. Clinical oral investigations 15(5): 649-656.

9. Khan N (2012) Time and sequence of eruption of permanent teeth in Pakistani children First database of Pakistani population Lap Lambert Academic Publishing, Pakistan.

10. Sami E, T Vichayanrat, P Satitvipawee (2016) Caries with Dental Fluorosis and Oral Health Behaviour Among 12-Year School Children in Moderate-Fluoride Drinking Water Community in Quetta, Pakistan. Journal of the College of Physicians and Surgeons Pakistan JCPSP 26(9): 744-747.

11. Dye BA (2004) The relationship between healthful eating practices and dental caries in children aged 2-5 years in the United States, 1988-1994. The Journal of the American Dental Association 135(1): 55-66.

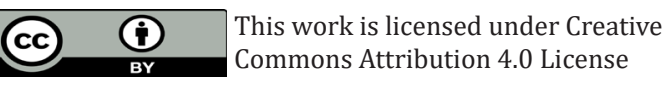

To Submit Your Article Click Here:

Submit Article

DOI: $10.32474 /$ IPDOAJ.2018.01.000122

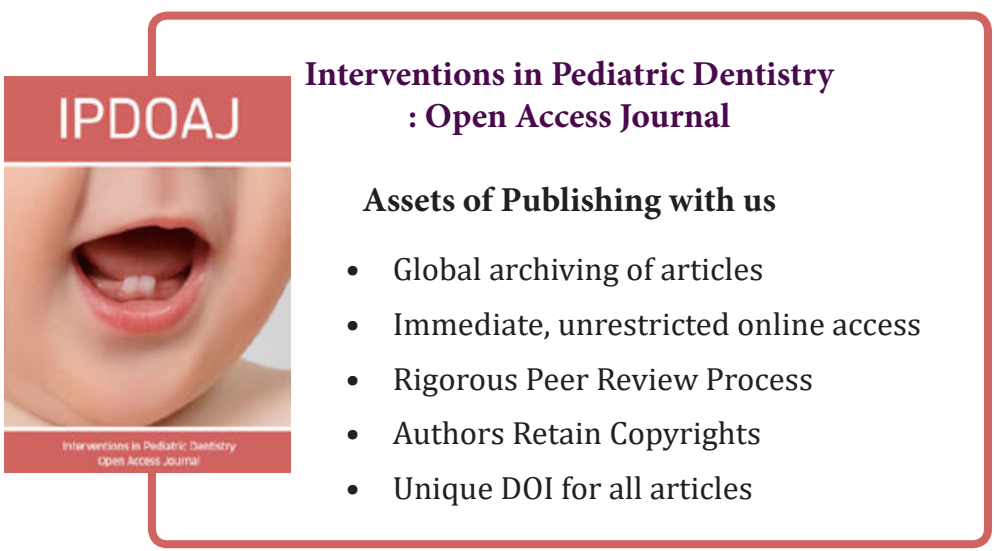

